\title{
Polylactic Acid as a Potential Alternatives of Traditional Plastic Packagings in Food Industry
}

\author{
T. Horváth ${ }^{1}$, T. J. SzABó2 ${ }^{2}$ K. MAROSSY \\ ${ }^{1}$ Institute of Ceramics and Polymer Engineering, Miskolc University, horvath.tibor70@upcmail.hu \\ ${ }^{2}$ Institute of Ceramics and Polymer Engineering, Miskolc University, polsztam@uni-miskolc.hu \\ ${ }^{3}$ Institute of Ceramics and Polymer Engineering, Miskolc University, polkal01@uni-miskolc.hu
}

Abstract. Huge quantity of synthetic polymers is used as packaging materials in different fields of food industries. A significant part of these polymers applied as a primary, direct food contact construction. The scoped application area is the sweet industry. In this field Polystyrol (PS), Polypropylene (PP) and Polyethylene-terephthalate (PET) have used but during the last fifteen years the usage of PET has been grown. In one hand the price of this material is efficient, form other hand the PET is the one of the most safe (for food industrial applications) petrol chemical plastic that can be used as primary or secondary food contact packaging material. To maximize the customer safety and minimize the environmental impact of traditional PET, a new bio-sourced and bio-degradable alternative polymer aimed to be used in this special food industrial segment. One of the potential alternatives is the Polylactic acid (PLA) that would be a possible substitute as it is compostable and produced from renewable sources and has good physical and mechanical properties [1].

\section{Introduction}

The mechanical and optical property of PLA is very similar to PET, but the PLA and its alternatives like PLLA, PDLA and PDLLA are more fragile in case of rapid stress, and less heat-resistant compared to the PET. The appropriate mechanical properties of substitute material are quite important because the further usage of recently applied thermo-forming methods and existing costly tools are basic requirements/expectation of the relevant industrial segment.

\begin{tabular}{|l|c|c|c|c|}
\hline Properties & PDLA & PLLA & PDLLA & PET \\
\hline Crystalline structure & Crystalline & Semi crystalline & Amorphous & $\begin{array}{c}\text { Amorphous and } \\
\text { semi-crystalline }\end{array}$ \\
\hline Melting temperature $\left(T_{m}\right)$ & $180^{\circ} \mathrm{C}$ & $180^{\circ} \mathrm{C}$ & variable & $260^{\circ} \mathrm{C}$ \\
\hline Glass transition temperature $\left(T_{g}\right)$ & $50-60^{\circ} \mathrm{C}$ & $50-60^{\circ} \mathrm{C}$ & variable & $67-81^{\circ} \mathrm{C}$ \\
\hline Half-life in $37^{\circ} \mathrm{C}$ normal saline & $4-6$ month & $4-6$ month & $2-3$ month & 700 year \\
\hline Elongation at break $(\%)$ & $20-30 \%$ & $20-30 \%$ & variable & $230 \%$ \\
\hline
\end{tabular}

Table 1. Physical and chemical parameters of the PLA and PET foils [2].

Although the average molar masses of these materials are different (PET $30000-80000 \mathrm{~g} \cdot \mathrm{mol}^{-1}$ [3]; PDLLA $100000-180000 \mathrm{~g} \cdot \mathrm{mol}^{-1}$ [4] and PLLA $100000-300000 \mathrm{~g} \cdot \mathrm{mol}^{-1}$ [5]) but the mechanical properties of material depends on other key factors over the average molar mass like structure of 
monomer and chemical structure of material. In this work two commercial PLA foils (PLLA and PDLLA) have been compared to the commercial PET foil. During the laboratory tests the mechanical, thermal and barrier properties and the structures of materials were analysed by tensile testing and differential scanning calorimetry.

\section{Experimental}

\subsection{Material and methods}

The PET and PDLLA samples were provided by Pro-Form Kft. The PLLA material has been purchased from Goodfellow Cambridge Ltd. The thicknesses of materials were $300 \mu \mathrm{m}$ for PET and PDLLA, in case of PLLA it was only $50 \mu \mathrm{m}$. Previously the glass transition temperatures were determined by DMA analysis performed on MetraviB 25 machine (Table 2.) Although the Tg of PDLLA is lower than PLLA's but it can be increased with increasing amount of L-lactic [6].

\begin{tabular}{|c|c|c|c|}
\hline Material & PDLA & PLLA & PET \\
\hline Glass transition temperature $(\mathrm{Tg})$ & $57^{\circ} \mathrm{C}$ & $62^{\circ} \mathrm{C}$ & $82^{\circ} \mathrm{C}$ \\
\hline
\end{tabular}

Table 2. Glass transition temperatures of PET, PDLA and PLLA foils.

The mechanical tests have been performed on INSTRON 5566 testing machine with the application of same test parameters for all materials (Table. 3). During the test ASTM D389 standard was followed. To make the changes be more visible and measurable, all samples were printed with splitting grid. The dimension of grid was $1 \mathrm{~mm}$ for PET film, in case of PDLLA and PLLA $10 \mathrm{~mm}$ splitting grid was applied.

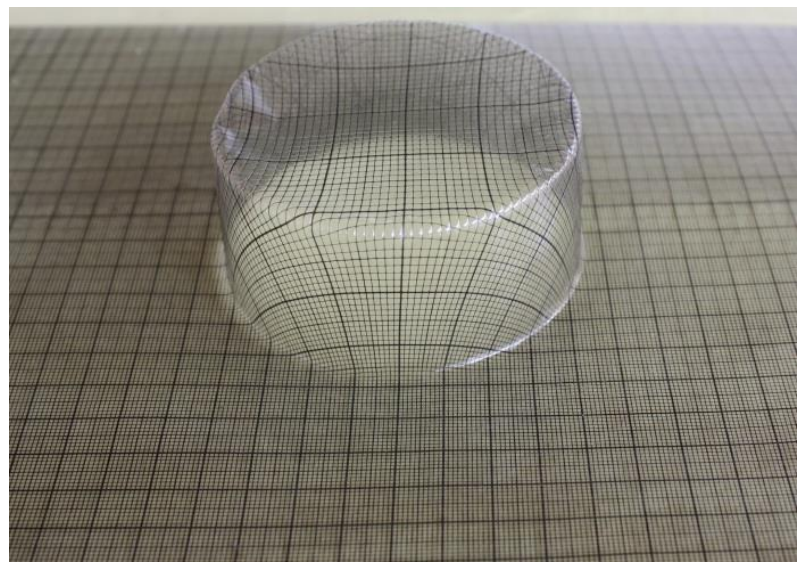

Figure 1. Printed splitting grid for thermo-forming experiments.

\begin{tabular}{|c|c|c|c|c|}
\hline Parameter & $\begin{array}{c}\text { Test speed } \\
\mathrm{mm} / \mathrm{min}\end{array}$ & $\begin{array}{c}\text { Test temperature } \\
{ }^{\circ} \mathrm{C}\end{array}$ & $\begin{array}{c}\text { Stretching level } \\
\mathrm{mm}\end{array}$ & $\begin{array}{c}\text { Sample dimensions } \\
\mathrm{mm}\end{array}$ \\
\hline Value & 100 & $23 \pm 1$ & $40,80,120$ & $100 \times 80$ \\
\hline
\end{tabular}

Table 3. Adjusted test parameters during mechanical analysis

The structures of materials were analysed with Differential scanning calorimetry (DSC) method on DSC131 Evo equipment with basic linear heating/cooling ramp that was chosen as $\mathrm{dT} / \mathrm{dt}=10^{\circ} \mathrm{C} \mathrm{min}{ }^{-1}$ [7]. 
International Journal of Engineering and Management Sciences (IJEMS) Vol. 5. (2020). No. 2

DOI: 10.21791/IJEMS.2020.2.16.

The heat range of analysis was $25-275^{\circ} \mathrm{C}$ for PET and PDLLA and $-125-245$ for PLLA.

\subsection{Mechanical properties of PET, PDLLA and PLLA}

All samples have been analysed by tensile test with deformation of $40 \mathrm{~mm}, 80 \mathrm{~mm}$ and $120 \mathrm{~mm}$. The result of the test proven that to get the same deformation value in case of PLLA and PDLLLA higher forming forces required than in case of PET (Table 5.).

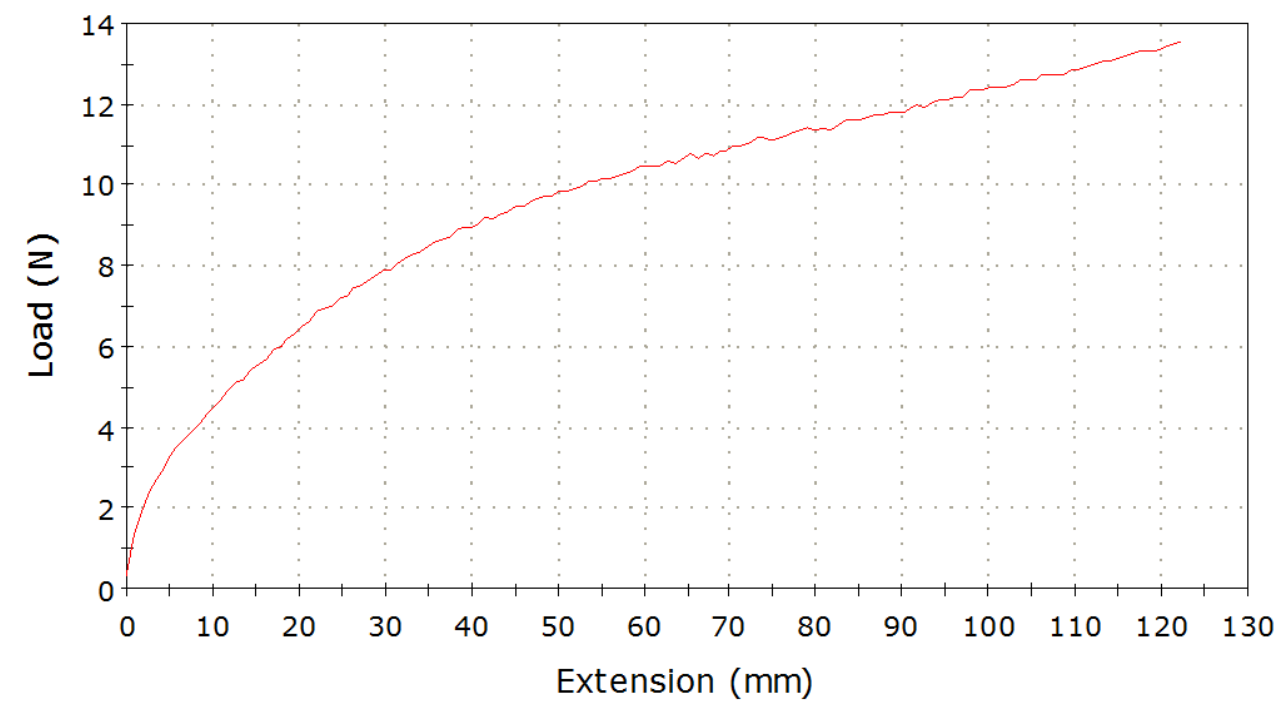

Figure 2. Load-extension curve of PLLA foil.

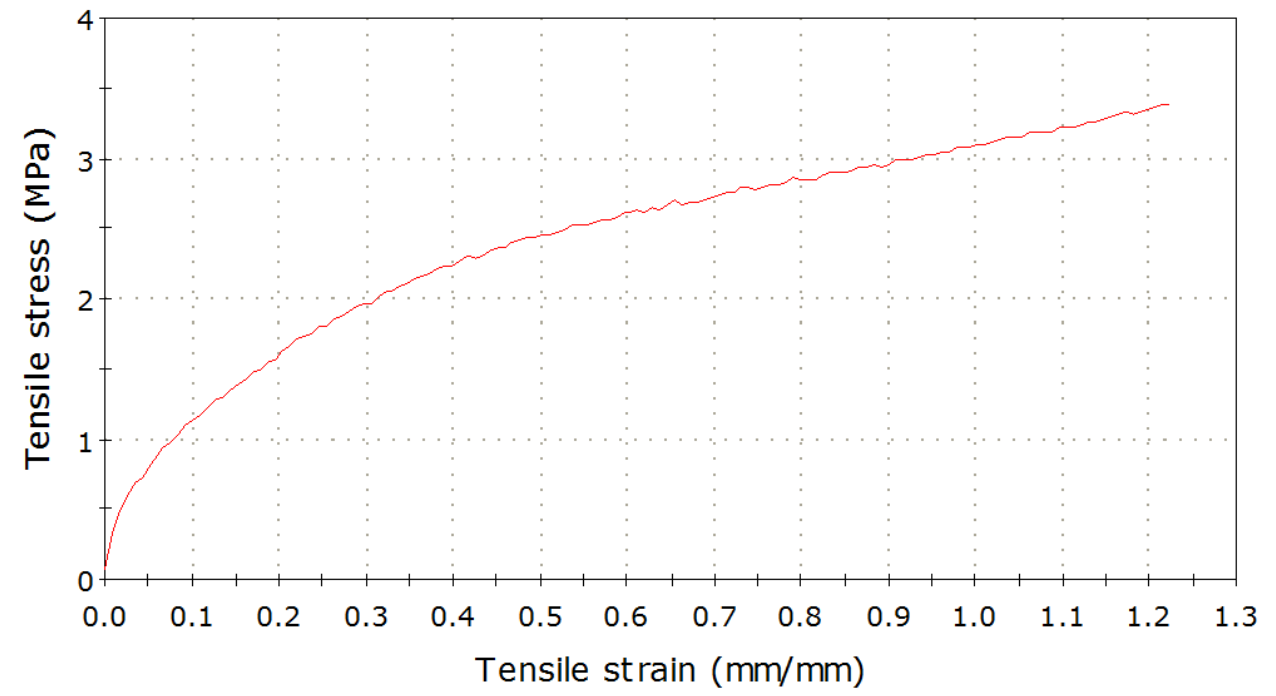

Figure 3. Tensile test result of PLLA foil.

\begin{tabular}{|c|c|c|c|}
\cline { 2 - 4 } \multicolumn{1}{c|}{} & \multicolumn{3}{c|}{ Strain $(\mathrm{mm})$} \\
\hline Material & $\mathbf{4 0}$ & $\mathbf{8 0}$ & $\mathbf{1 2 0}$ \\
\hline PET (Mpa) & 0.74 & 0.80 & 0.78 \\
\hline PDLLA (MPA) & 0.90 & 1.22 & 1.42 \\
\hline PLLA (Mpa) & 1.51 & 2.71 & 3.36 \\
\hline
\end{tabular}

Table 4. Tensile stress maximums of PET, PDLLA and PLLA foils. 


\subsection{DSC analysis of PET, PDLLA and PLLA}

With DSC analysis all of three materials were tested. All specific phases like the relaxation (to release the remaining forming stress of materials), the re-crystallization and de-crystallization phases could be observed and identified at all materials.

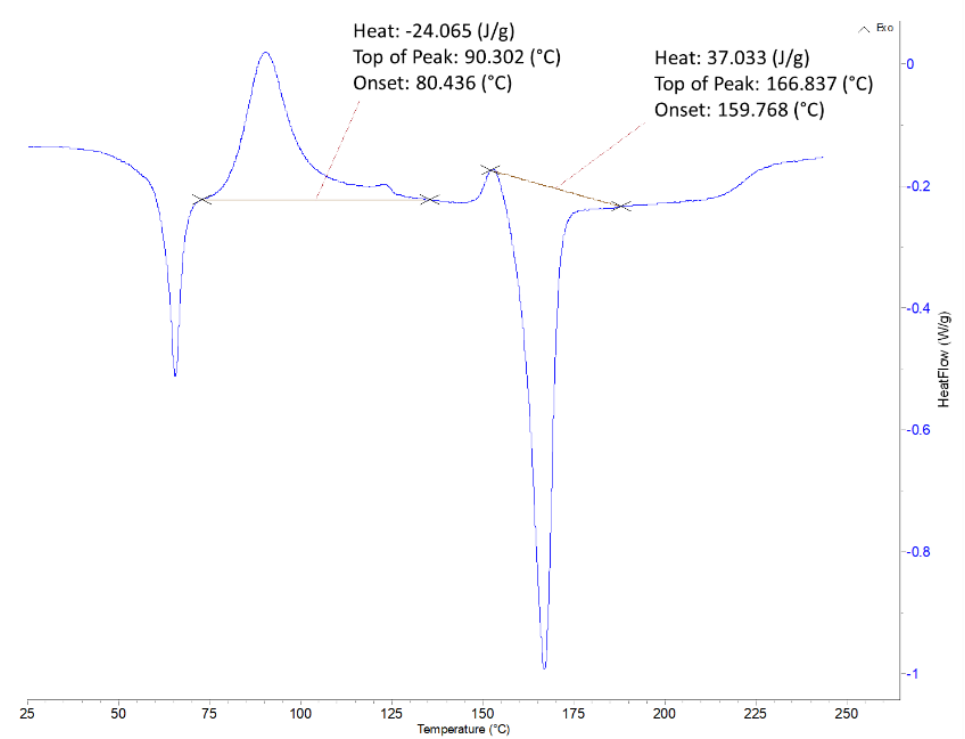

Figure 4. Results of DSC analysis of PLLA.

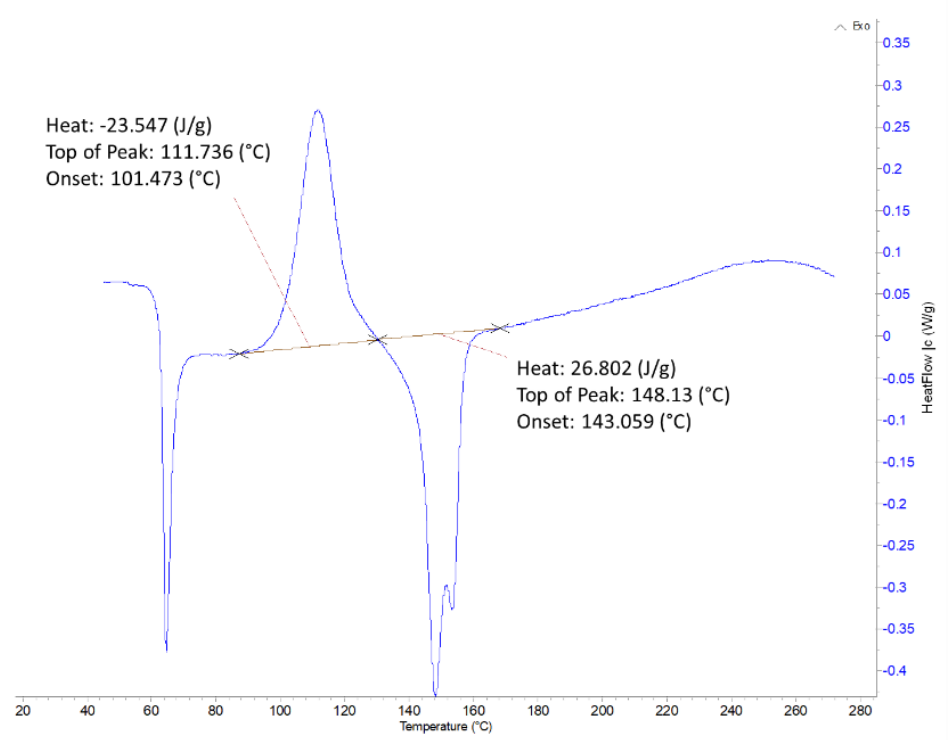

Figure 5. Results of DSC analysis of PDLLA. 


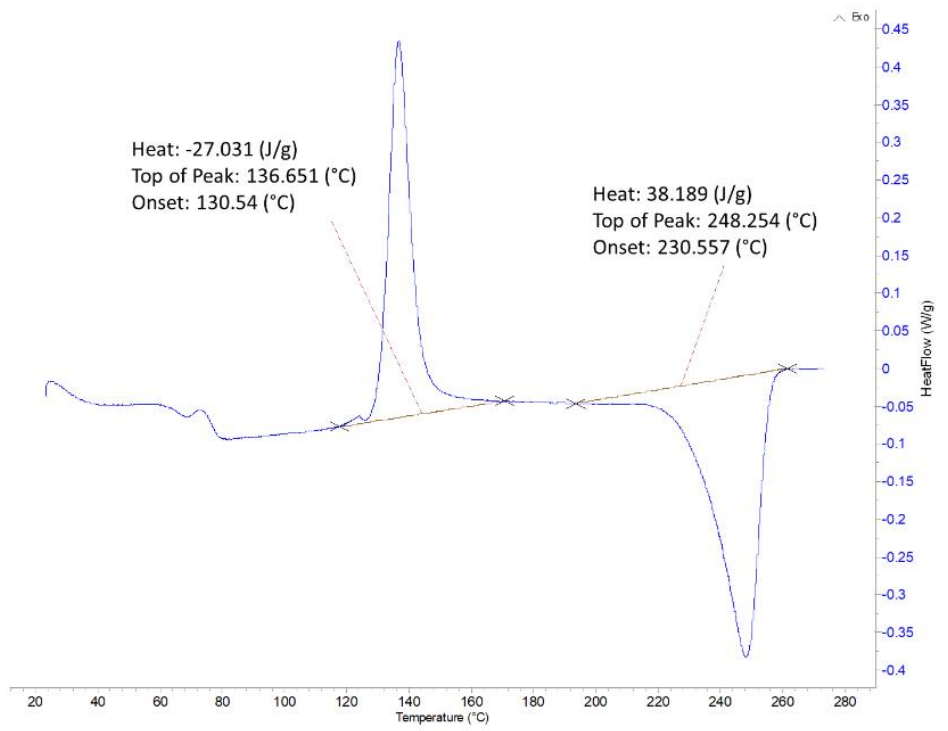

Figure 6. Results of DSC analysis of PET.

In case of PDLLA the de-crystallisation could be divided for two main processes. The PDLLA contains $\mathrm{L}$ and D isomers and these isomers can format different crystal structures which caused that duplicated de-crystallization processes at the temperature range of $140-160{ }^{\circ} \mathrm{C}$. With the produced data (enthalpy area of melt and post-crystallization) the crystal contents of materials could be calculated based on the following equation [8]:

$$
\begin{aligned}
& K_{\%}=\frac{\Delta \mathrm{H}_{m}}{\Delta \mathrm{H}_{c}} \times 100 \\
& K_{i(\%)}=\frac{\mathrm{H}_{m}-\mathrm{H}_{c}}{\mathrm{H}_{l i t}} \times 100
\end{aligned}
$$

\begin{tabular}{|c|c|c|c|c|}
\hline Material Type & PET & PET $_{\text {recycled }}$ & PDLLA & PLLA \\
\hline$\Delta \mathrm{H}_{m}$ Enthalpy of crystallisation $\left(\mathrm{J} \cdot \mathrm{g}^{-1}\right)$ & -27.03 & -26.72 & -23.55 & -24.07 \\
\hline$\Delta \mathrm{H}_{C}$ Enthalpy of decrystallisation $\left(\mathrm{J} \cdot \mathrm{g}^{-1}\right)$ & 38.19 & 38.61 & 26.80 & 37.03 \\
\hline$\Delta \mathrm{H}_{l i t}$ Enthalpy of $100 \%$ crystalline polymer $\left(\mathrm{J} \cdot \mathrm{g}^{-1}\right)$ & 140 & 140 & 93 & 93 \\
\hline Percentage of crystallinity (\%) & 7.97 & 8,5 & 3.5 & 13.94 \\
\hline
\end{tabular}

Table 5. Percentage of crystallinity of PETS, PDLLA and PLLA foils at first heating run.

\begin{tabular}{|c|c|c|c|}
\hline Strain (mm) & $\mathbf{4 0}$ & $\mathbf{8 0}$ & $\mathbf{1 2 0}$ \\
\hline Percentage of crystallinity (\%) at 1st heating run & 4 & 1,20 & 1,40 \\
\hline Percentage of crystallinity (\%) at 2nd heating run & 28,20 & 27,20 & 26,70 \\
\hline
\end{tabular}

Table 6. Change of crystallinity of PDLLA at different strains and heating runs.

\begin{tabular}{|c|c|c|}
\hline Material & PLLA & PDLLA \\
\hline Percentage of crystallinity at 1st heating run (\%) & 23 & 3,4 \\
\hline Percentage of crystallinity at 2nd heating run (\%) & 69 & 28,1 \\
\hline
\end{tabular}

Table 7. Change of crystallinity of PLLA and PDLLA alternative samples at different heating runs. 


\section{Results}

The PET and PLA foils were analysed by both mechanical and DSC analysis methods. The results confirmed that the analysed PLA samples (polylactic-acid) have better mechanical properties to forming it in higher load range. In case of material structures the PLLA and PET are mostly amorphous with crystallinity ratio of $14 \%$ and $8 \%$. The PDLLA (crystallinity ratio is only 3,5\%) contains both lactic-acid isomers ( $\mathrm{L}$ and $\mathrm{D}$ ) and this heterogeneous system causes irregularity in molecular chains and negative impact on physical properties compared to the PLLA. Although the low crystallinity of PLA leading to inferior thermostability problems during its long service life, the high crystal ratio makes the material more rigid which causing alternative problems during the application of material [9]. In case of appropriate conditions the crystallization process of PLLA is easier compared to the PDLLA as this material has only one component. The final structure of PLLA is more stable because the molecular chain irregularity - which caused by stereochemical effects of different isomers - is minor in this case and in PLLA three main crystal forms can usually be formed ( $\alpha, \beta$, and $\gamma$ crystal forms) [10].

\section{Conclusion}

During the analysis, it is confirmed the PLA (as PLLA and PDLLA) is more resistant against the forming forces, so the load bearing performance of material is better compared to the recently used PET. The strengths of the PLA are the load bearing specific attribution, the lower forming temperature and the bio-sourced production of this material and the most important bio-degradability. Unfortunately the relatively low glass transition temperature of PLA is the weakness of this material at the same time, because the application of this material could be only accepted for those kind of foodstuff where the temperature of packaing process is lower than the $\mathrm{T}_{\mathrm{g}}$ of this material.

\section{Acknowledgments}

The described work was carried out as part of a project supported by the National Research, Development and Innovation Office - NKFIH, K123456.

\section{References}

[1] Y. Ikada, H. Tsuji, Macromol. - Biodegradable polyesters for medical and ecological applications Rapid Comm., 2000, 21, 117.

[2] Xiao L, Wang B, Yang G, Gauthier M (2012) Poly(Lactic Acid)-Based Biomaterials: Synthesis, Modification and Applications. Biomedical Science, Engineering and Technology, 247-282.

[3] Dr. Bánhegyi Gy (2005) Poli(etilén-tereftalát) (PET) újrafeldolgozása a tulajdonságok javításával. Műanyagipari szemle 5.

[4] http://www.bmg-inc.com/en/prod_and_res/bio_degmer/pdlla.html downloaded at: 28.10 .2019 
International Journal of Engineering and Management Sciences (IJEMS) Vol. 5. (2020). No. 2

DOI: 10.21791/IJEMS.2020.2.16.

[5] Ikada Y, Tsuji H (2000) Biodegradable polyesters for medical and ecological applications. Macromol. Rapid Commun. 21, 117-132.

[6] Dorgan J.R., Jansen J., Clayton M.P., Hait S.B., Knauss D.M. Melt rheology of variable L-content poly(lactic acid) J. Rheol. 2005; 49:607-619.

[7] Michael Arthur Cuiffo, Jeffrey Snyder, Alicia M. Elliott, Nicholas Romero, Sandhiya Kannan and Gary P. Halada - Impact of the Fused Deposition (FDM) PrintingProcess on Polylactic Acid (PLA) Chemistryand Structure - Applied Sciences 2017, 7(6), 579.

[8] https://www.netzsch-thermal-analysis.com/ru/promyshlennost-otrasli/glossary/crystallinitydegree-of-crystallinity/

downloaded at: 29.10 .2019

[9] Shikui Jia, Demei Y, Yan Zhu, Zhong Wang, Ligui Chen and Lei Fu - Morphology, Crystallization and Thermal Behaviors of PLA-Based Composites: Wonderful Effects of Hybrid GO/PEG via Dynamic Impregnating - Polymers 2017, 9(10), 528.

[10] Jingqing Li, Peitao Xiao, Hongfei Li , Yao Zhang, Feifei Xue, Baojing Luo, Shaoyong Huang, Yingrui Shang, Huiying Wen, Jesper de Claville Christiansen, Donghong Yu and Shichun Jiang - Crystalline structures and crystallization behaviors of poly(L-lactide) in poly(L-lactide)/graphene nanosheet composites - Polym. Chem., 2015, 6, 3988-4002. 